\title{
Sonerila cardamomensis (Melastomataceae), a new species from Cambodia
}

\author{
Jae-Seo Shin', Bo-Kyeong Song', Chhang Phourin², \\ Hyosig Won ${ }^{3}$, Kyong-Eun Lee ${ }^{3}$, Seong-Hyun $\mathrm{Cho}^{4}$
}

I Department of Life Science, Hallym University, 1 Hallymdaehak-gil, Chuncheon-si, Gangwon 24252, South Korea 2 Forestry Administration, 40 Preah Norodom Blvd, Phnom Penh, Kingdom of Cambodia 3 Department of Biological Science, Daegu University, Gyeongsan 38453, South Korea 4 National Institute of Biological Resources, Incheon 22689, South Korea

Corresponding author: Seong-Hyun Cho (dricetea1@gmail.com)

Academic editor: Ricardo Kriebel | Received 26 June 2020 | Accepted 22 July 2020 | Published 21 August 2020

Citation: Shin J-S, Song B-K, Phourin C, Won H, Lee K-E, Cho S-H (2020) Sonerila cardamomensis (Melastomataceae), a new species from Cambodia. PhytoKeys 156: 139-144. https://doi.org/10.3897/phytokeys.156.55866

\begin{abstract}
Sonerila cardamomensis, a new species of family Melastomataceae from the Central Cardamom Protected Area in Koh Kong province of southwestern Cambodia, is described and illustrated. The species is similar to $S$. violifolia Hook.f. ex Triana, but is readily distinguished by its cordate leaf base, lack of setae at the nodes, longer pedicels, smaller petals, smaller hypanthiums and smaller capsules.
\end{abstract}

\section{Keywords}

Cambodia, Central Cardamom Protected Area, new species, Sonerila

\section{Introduction}

Melastomataceae Juss. consists of approximately 166 genera and 4,200-4,500 species which are distributed in both the New World (about 2,950 species) and the Old World (1,275-1,550 species) (Renner 1993, Michelangeli et al. 2013). In Cambodia, Melastomataceae are currently represented by 34 species and 6 varieties for a total of 40 taxa in 9 genera (Cho et al. 2015, Tagane et al. 2015, Cho et al. 2016a, Cho et al. 2016b). The most species-rich genera in Cambodia are Memecylon L. (18 species), Osbeckia L. (7 species), and Melastoma L. (5 species). 
In Indochina, there are around 22 species of Sonerila and the present count includes 9 species from Vietnam, 13 species from Thailand and 4 from Laos (Guillaumin 1913, Ho 1999, Renner et al. 2001, Chen and Renner 2007, Newman et al. 2007). In Cambodia, at the beginning of the $20^{\text {th }}$ century, only one species was described, namely Sonerila quadrangularis (synonym of S. maculata Roxb.). Three species are reported in the present account, namely S. bokorense S.H. Cho \& Y.D. Kim, S. maculata Roxb., and S. plagiocardia Diels (Cho et al. 2016a).

During the recent floristic survey, one species of Sonerila was collected at Thmor Bang District of the Central Cardamom Protected Area in Koh Kong province of southwestern Cambodia that does not appear to be similar to previously described species (Fig. 1, 2). It is the most similar to Sonerila violifolia Hook.f. ex Triana, but detailed examination of the morphology revealed that it differs from $S$. violifolia. Therefore, it is described here as a new species.

\section{Taxonomy}

\section{Sonerila cardamomensis S.H.Cho, sp. nov.}

urn:Isid:ipni.org:names:77211172-1

Figures 1, 2

Type. Cambodia. Koh Kong Province, Central Cardamom Protected Area, sandstone rocky area in evergreen forest, $11^{\circ} 42^{\prime} 08.0^{\prime \prime} \mathrm{N}, 103^{\circ} 26^{\prime} 22.5^{\prime \prime E}$, a.s.1. $427 \mathrm{~m}, 9$ August 2018, with flowers, Cho S.H., Shin J.S., Song B.K., Chhang Phourin CB-4467 (holotype $\mathrm{KB}$ !, isotypes $\mathrm{KB}$ !, $\mathrm{K}$ !, $\mathrm{P}$ !).

Diagnosis. Sonerila cardamomensis is most similar to S. violifolia Hook.f. ex Triana, which is distributed in Myanmar and Thailand but is readily distinguished from the latter by the cordate leaf base, lack of setae at the nodes, longer pedicels, smaller petals, smaller hypanthia and smaller capsules (Table 1).

Description. Perennial, herbs, terrestrial, 4-7 cm high, 1 (or rarely 2) shoot from rhizome. Rhizome short, bulbous, $0.4-1.0 \mathrm{~cm}$ in diam. Stems 4-sided, tinged purplish, the internodes almost absent. Leaves simple, membranous, opposite, clustered at base, those of a pair isomorphic; petioles $0.4-2.5 \mathrm{~cm}$, glandular trichome; leaf blade ovate, $1.0-4.0 \times 0.9-2.7 \mathrm{~cm}$, apex acute, rarely obtuse, base cordate, upper surface covered with glandular trichome, lower surface slightly covered with glandular trichome, lateral primary vein 2-3 pairs, departing at the base, margin serrate. Inflorescences pedunculate, 1-5[7] scorpioid cymes with 5 to 11 flowers; peduncle [1.5]3.0-5.0 cm (up to $8.0 \mathrm{~cm}$ long when fruiting), angular with glandular trichome. Pedicel ca. $4.0 \mathrm{~mm}$ long (up to $5.0 \mathrm{~mm}$ long when fruiting), with glandular trichomes. Flowers bisexual, 3-merous. Hypanthium campanulate, 3-angled, 6-ribbed, $3.5 \times 1.3-1.5 \mathrm{~mm}$, with glandular trichomes. Calyx lobes broadly triangular $0.7 \times 1.0 \mathrm{~mm}$, apex acute. Petals 3, thin, 5.5-6.0 × 3.5-4.0 mm, ovate-obovate, apex acute to acuminate, pink to purplish pink, abaxially glandular trichome on midveins, adaxially glabrous. Stamens 3, isomorphic; filaments distinct, 3.7-4.0 

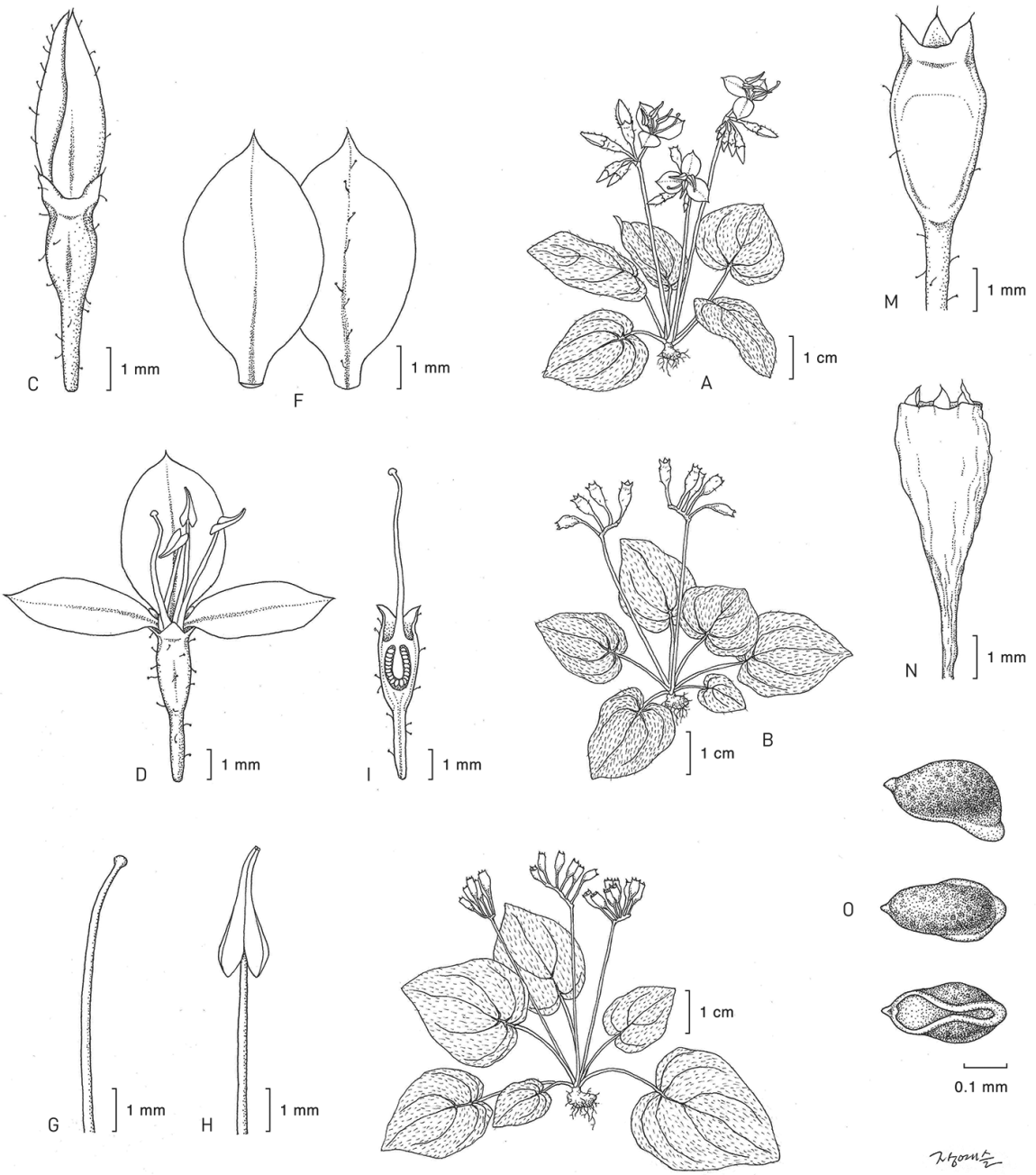

0
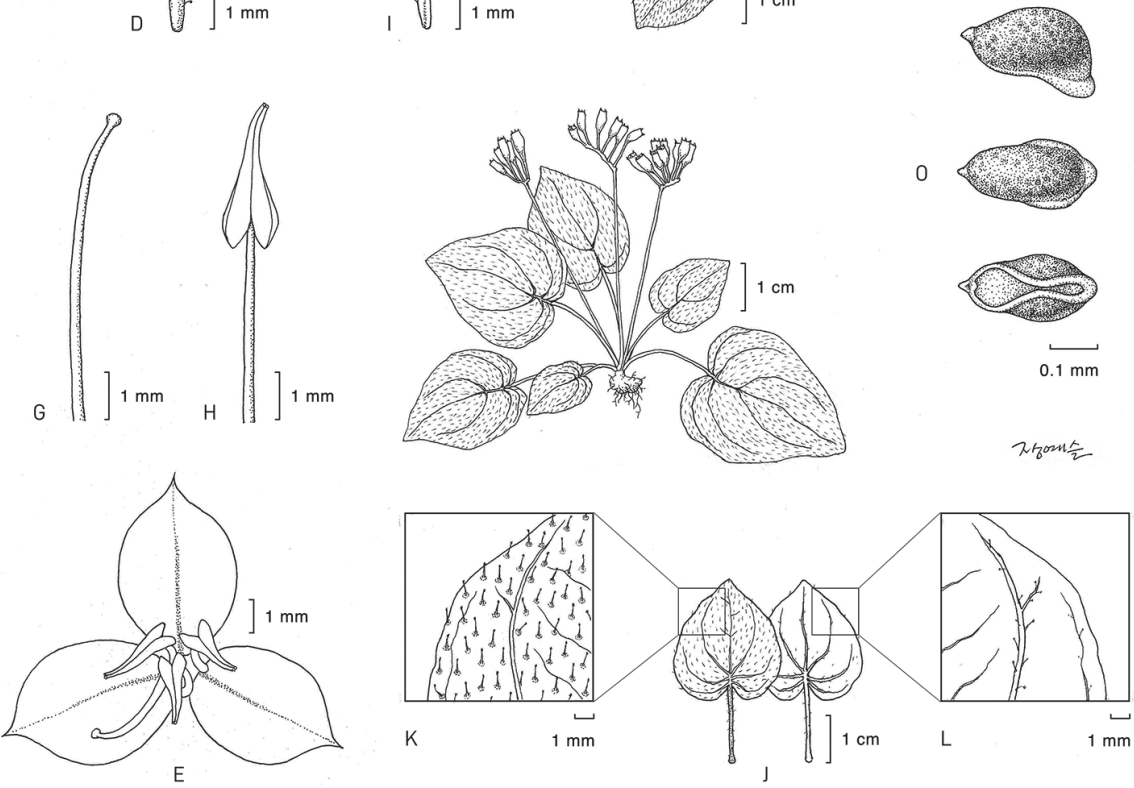

Figure I. Sonerila cardamomensis A Flowering individual B fruiting individual C-D developing flower $\mathbf{E}$ mature flower $\mathbf{F}$ petals (right: abaxial, left: adaxial) $\mathbf{G}$ style and Stigma $\mathbf{H}$ filament and Anther $\mathbf{I}$ gynoecium J leaf $\mathbf{K}$ upper surface of leaf $\mathbf{L}$ lower surface of leaf $\mathbf{M}$ immature capsule $\mathbf{N}$ mature capsule $\mathbf{O}$ seeds: Cho et al. CB-4467. Illustration by Ye-Seul Jang.

$\mathrm{mm}$, glabrous, pinkish; anthers ca. $4.5 \mathrm{~mm}$, lanceolate, deeply cordate to sagittate at the base, apex acute, yellow, dehiscence poricidal. Ovary inferior, urceolate, apex with a membranous 3-lobed crown, ovules numerous, placentation axillary; style 

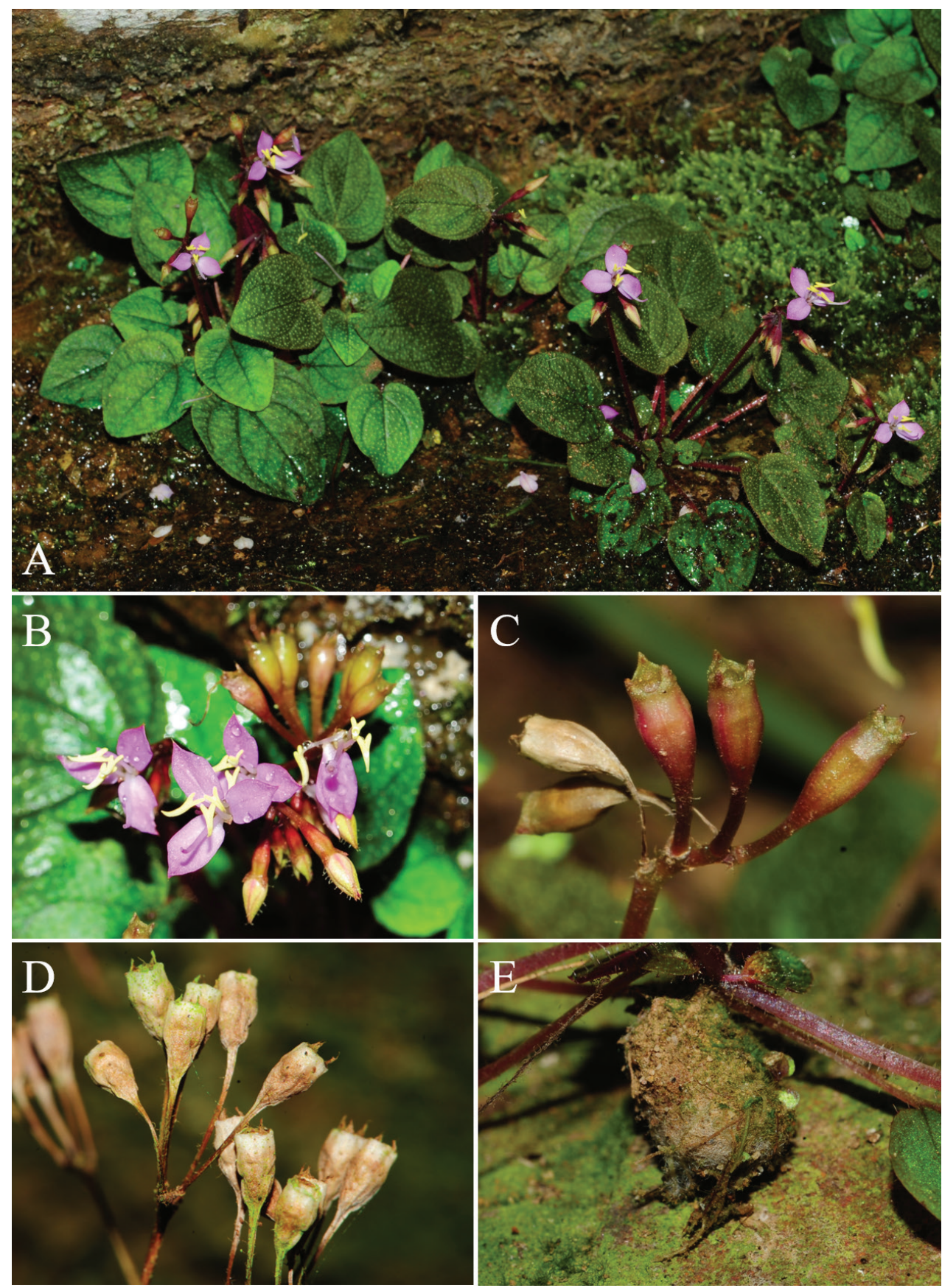

Figure 2. A-E Sonerila cardamomensis $\mathbf{A}$ habit $\mathbf{B}$ flowers $\mathbf{C}$ immature capsules $\mathbf{D}$ mature capsules $\mathbf{E}$ short bulbous rhizome: Photos by Seong-Hyun Cho. 
Table I. Comparison of key features of Sonerila cardamomensis and S. violifolia.

\begin{tabular}{lcc}
\hline \multicolumn{1}{c}{ Taxonomic traits } & Sonerila cardamomensis & S. violifolia \\
\hline Stem setae at the nodes & Absent & reddish brown, $4.0-6.0 \mathrm{~mm}$ long \\
Leaf upper surface base & glandular trichomes cordate & spares minute bristly hairs obtuse or cuneate \\
Pedicel & ca. $4.0 \mathrm{~mm}$ long & $2.0-3.0 \mathrm{~mm}$ long \\
Hypanthium & ca. $3.5 \mathrm{~mm}$ long & $5.0-6.0 \mathrm{~mm}$ long \\
Petal & $5.5-6.0 \mathrm{~mm}$ long & $8.0-10.0 \mathrm{~mm}$ long \\
Capsule & $3.5-4.0 \mathrm{~mm}$ long & $6.0-7.0 \mathrm{~mm}$ long \\
\hline
\end{tabular}

filiform, $6.6-7.3 \mathrm{~mm}$, glabrous, pink; stigma apiculate. Fruit a capsule, campanulate, $3.5-4.0 \times 2.0-2.2 \mathrm{~mm}, 6$ longitudinal ribs, glabrous. Seeds cuneate, numerous, ca. $0.3 \mathrm{~mm}$, light brown.

Specimen examined. Cambodia. 9 August 2018, with flowers, Cho et al. CB4469, 4471, 4473 (KB!), Won et al. 16499, 16506(DGU!); 15 January 2019, with fruits, Cho et al. CB-4614, 4615 (KB!)

Phenology. Fls July to August; Frts August to November.

Distribution and habitat. Sonerila cardamomensis grows on sandstone rocky area in evergreen forest from 420 to 600 m.a.s.l. Endemic to southwestern Cambodia, $S$. cardamomensis is at present known only in the Central Cardamom Protected Area in Koh Kong province.

Conservation status. Sonerila cardamomensis was collected in the Central Cardamom Protected Area of Koh Kong province in southwestern Cambodia. Until now, two big populations are known, each composed of more than ca. 1,000 individuals, and was discovered in the protected area. Therefore, it is preliminarily classified as data deficient (DD) according to the IUCN Red List criteria.

\section{Acknowledgements}

We thank Ms. Ye-Seul Jang for preparing the line drawing. This work was supported by a grant from the National Institute of Biological Resources (NIBR), funded by the Ministry of Environment (MOE) of the Republic of Korea (NIBR202006101).

\section{References}

Chen J, Renner SS (2007) Sonerila Roxburgh. In: Wu, Z-Y. Raven PH (Eds) Flora of China 13. Science Press, Beijing and Missouri Botanical Garden Press, St. Louis, 390-392.

Cho SH, Lee JH, Won H, Phourin C, Kim YD (2015) Sonerila bokorense (Melastomataceae), a new species from Cambodia. Phytotaxa 222(4): 295-299. https://doi.org/10.11646/phytotaxa.222.4.8 
Cho SH, Phourin C, Kim YD (2016a) A checklist for the seed plants of Cambodia. National Institute of Biological Resources, Ministry of Environment, Incheon, Korea. 130.

Cho SH, Kim BY, Lee JH, Phourin C (2016b) Two newly recorded species of the genus Medinilla from Cambodia. Korean Journal of Plant Taxonomy 46(3): 301-305. https:// doi.org/10.11110/kjpt.2016.46.3.301

Guillaumin A (1913) Melastomataceae. In: Lecomte MH, Gagnepain F (Eds) Flore Generale de l'Indo-Chine 2: 864-936.

Ho PH (1999) An Illustrated Flora of Vietnam 2. Ho Chi Minh City, Vietnam, 90-92. [in Vietnamese]

Michelangeli FA, Guimaraes PJF, Penneys DS, Almeda F, Kriebel R (2013) Phylogenetic relationships and distribution of new world Melastomeae (Melastomataceae). Botanical Journal of the Linnean Society 171(1): 38-60. https://doi.org/10.1111/j.1095-8339.2012.01295.x

Newman M, Ketphanh S, Svengsuksa B, Thomas P, Sengdala K, Lamxay V, Armstrong K (2007) A checklist of the vascular plants of Lao PDR. Royal Botanic Garden Edinburgh, 226-227.

Renner SS (1993) Phylogeny and classification of the Melastomataceae and Memecylaceae. Nordic Journal of Botany 13(5): 519-593.

Renner SS, Clausing G, Cellinese N, Meyer K (2001) Sonerila. In: Larsen K, Nielsen I (Eds) Flora of Thailand 7. The Forest Herbarium, Royal Forest Department, Bangkok, Thailand, 482-497. https://doi.org/10.1111/j.1756-1051.1993.tb00096.x

Tagane S, Toyama H, Chhang P, Nagamasu H, Yahara T (2015) Flora of Bokor National Park, Cambodia I: Thirteen new species and one change in status. Acta Phytotaxonomica et Geobotanica 66(2): 95-135. 